\title{
An Exploratory Analysis of Intelligent Manufacturing System (Ims) Under Fuzzy Utopian Environment
}

\author{
Uttam Kumar Mandal ${ }^{1}$, Bijan Sarkar ${ }^{2}$ \\ ${ }^{I}$ Department of Productionl Engineering, National Institute of Technology, Agartala, India \\ ${ }^{2}$ Department of Production Engineering, Jadavpur University, Kolkata, India
}

\begin{abstract}
With the emergence of a business era that embraces change as one of its major characteristics, manufacturing success and survival are becoming more and more difficult to ensure. The emphasis is on adaptability to changes in the business environment and on addressing market and customer needs proactively. Changes in the business environment due to varying needs of the customers lead to uncertainty in the decision parameters. Flexibility is needed in the CBR environment to counter the uncertainty in the decision parameters. The paper explores the relationship among lead-time, cost, quality, and service level and the leanness and agility of a case based reasoning in fast moving consumer goods business. The paper concludes with the justification of the framework, which analyses the effect of market winning criteria and market qualifying criteria on the three types of manufacturing system: lean, agile and le-agile. Finally, selection of the best manufacturing system applying COPRAS method with the help of case indexing and AHP. It is for the measuring of the weight factor of the problem.
\end{abstract}

Keywords: - Intelligent manufacturing systems, CBR, case Indexing, COPRAS method, analytic hierarchy process (AHP) and Fuzzy numbers.

\section{INTRODUCTION}

Basic definition of IMS is: Intelligent manufacturing system presents system with autonomous ability to adapt to unexpected changes, i.e. change of assortment, market requests, technology changes, social needs etc. In specific type of construction of IMS should be cared about following requests: low production costs, universality, adaptation of production system to specific product, precision and high quality of manufactured products, expressive shortening of main and incidental production times, exclusion of man in production process, safety with growth of requirements to manufacturing systems, come other criteria, which would widen abilities of manufacturing system. Requirements can be defined by changing character of production.

Goal is to create such a system, which is capable to react flexible to various situation in production process: to change of shape of manufactured product, change of measurement properties of product, packing of subsystems with components, unexpected switch to different type of products, time variation in production process, change of technological parameters, securing against crash situations.

Further is possible to define IMS as follows: Intelligent manufacturing system is possible to consider as higher phase of flexible manufacturing systems.

Significant interest has been shown in recent years in the idea of "lean manufacturing", and the wider concepts of the "lean enterprises". The focus of the lean approach has essentially been on the elimination of waste or muda. The upsurge of interest in lean manufacturing can be traced to the Toyota Production Systems with its focus on the reduction and elimination of waste. Lean is about doing more with less. Lean concepts work well where demand is relatively stable and hence predictable and where variety is low. Conversely, in those contexts where demand is volatile and the customer requirement for variety is high, a much higher level of agility is required. Leanness may be an element of agility in certain circumstances, but it will not enable the organization to meet the precise needs of the customers more rapidly.

Agility is a business-wide capability that embraces organizational structures, information systems, logistics processes and in particular, mindsets (Power et al., 2001; Katayama and Bennett, 1999). Agility is being defined as the ability of an organization to respond rapidly to changes in demand, both in terms of volume and variety (Christopher, 2000). The lean and agile paradigms, though distinctly different, can be and have been combined within successfully designed and operated total supply chains (Mason-Jones and Towill, 1999).

Distinguishing attribute Lean manufacturing system Agile manufacturing system Le-agile manufacturing system 
An Exploratory Analysis of Intelligent Manufacturing System (Ims) Under Fuzzy Utopian

Table-1: Comparison of Lean, Agile and Le-agile manufacturing systems

\begin{tabular}{llll}
\hline Market demand & Predictable & Volatile & Volatile and unpredictable \\
Product variety & Low & High & Medium \\
Product life cycle & Long & Short & Short \\
Customer drivers & Cost & Lead-time and availability & Service level \\
Profit margin & Low & High & Moderate \\
Dominant costs & Physical costs & Marketability costs & Both \\
Stock out penalties & Long term contractual & Immediate and volatile & No place for stock out \\
Purchasing policy & Buy goods & Assign capacity & Vendor managed inventory \\
Information enrichment & Highly desirable & Obligatory & Essential \\
Forecast mechanism & Algorithmic & Consultative & Both/either \\
Typical products & Commodities & Fashion goods & Product as per customer demand \\
Lead time compression & Essential & Essential & Desirable \\
Eliminate muda & Essential & Desirable & Arbitrary \\
Rapid reconfiguration & Desirable & Essential & Essential \\
Robustness & Arbitrary & Essential & Desirable \\
Quality & Market qualifier & Market qualifier & Market qualifier \\
Cost & Market winner & Market qualifier & Market winner \\
Lead-time & Market qualifier & Market qualifier & Market qualifier \\
Service level & Market qualifier & Market winner & Market winner \\
\hline
\end{tabular}

The past studies show how the need for agility and leanness depends upon the total supply chain strategy, particularly considering market knowledge, via information enrichment, and positioning of the decoupling point. Combining agility and leanness in one SC via the strategic use of a de-coupling point has been termed "le-agility"' (Naylor et al., 1999). Therefore le-agile is the combination of the lean and agile paradigms within a total supply chain strategy by positioning the decoupling point so as to best suit the need for responding to a volatile demand down stream yet providing level scheduling upstream from the market place (van Hoek et al., 2001). The decoupling point is in the material flow streams to which the customer orders penetrates (MasonJones et al., 2000a, b; Prince and Kay, 2003). Table 1 illustrates the comparison of attributes among lean, agile and le-agile manufacturing systems.

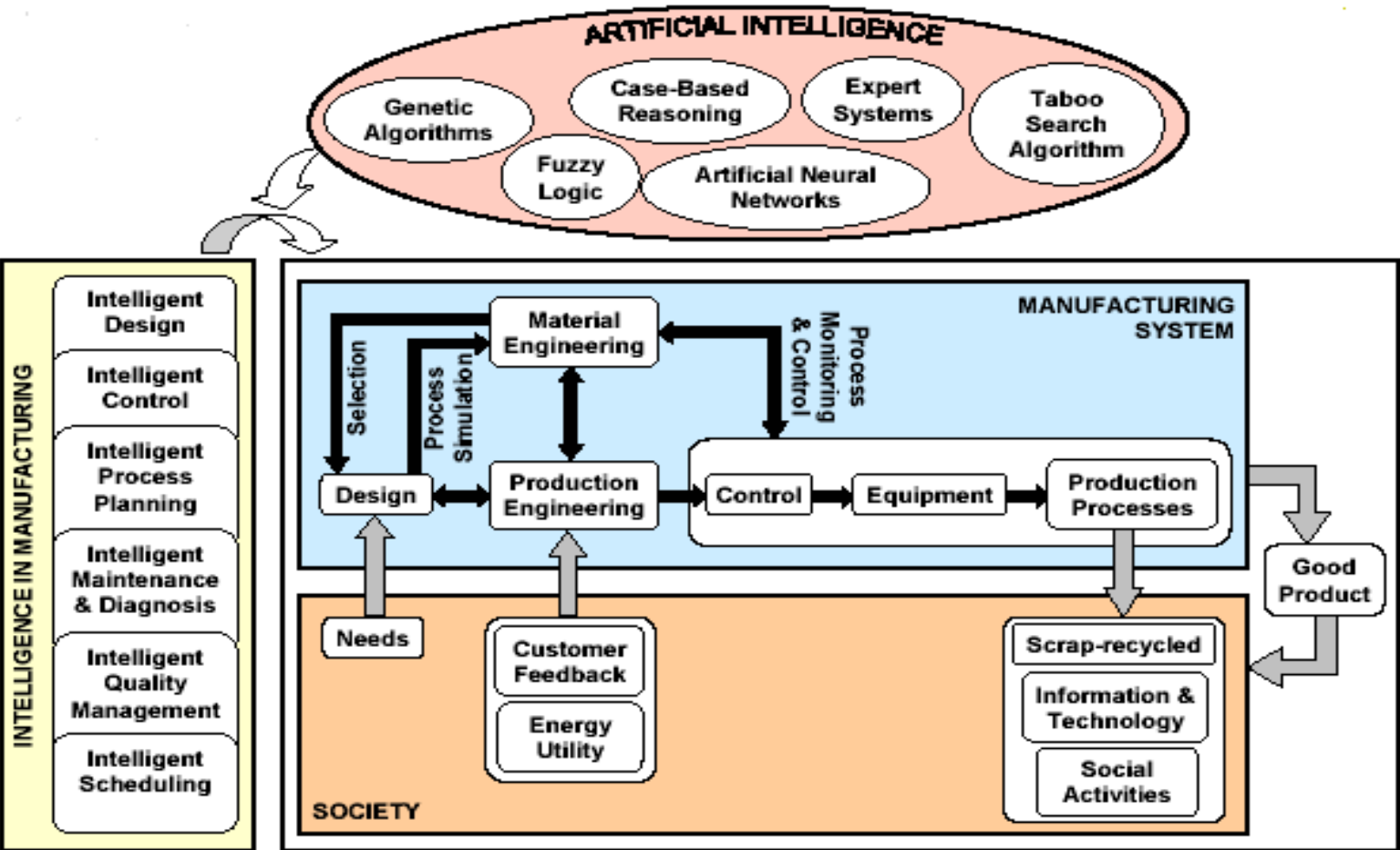

Figure-1: Whole domain of intelligent manufacturing system and inter-related with the CBR, AHP and Fuzzy system

The selection of an optimal manufacturing system for an intelligent manufacturing system from among two or more alternative systems on the basis of two or more attributes is a multiple attribute complex proportional assessment decision making problem. The selection decisions are complex, as manufacturing selection is more challenging today. There is a need for simple, systematic, and logical methods or mathematical tools to guide decision makers in considering a number of selection attributes and their interrelations. 
The objective of any manufacturing selection procedure is to identify appropriate selection attributes, and obtain the most appropriate combination of attributes in conjunction with the real requirement. Thus, efforts need to be extended to identify those attributes that influence material selection for a given engineering design to eliminate unsuitable alternatives, and to select the most appropriate alternative using simple and logical methods.

\section{Case-based Reasoning}

CBR, Case-based Reasoning, is a popular method in artificial intelligence because it is very simple and reasonable. Especially, in dealing with complex issues and multi-attribute decision-making, In fact, CBR has many advantages, the most important one is that it can simulate the human thinking to solve problem and make decision. The figure of CBR given in below.

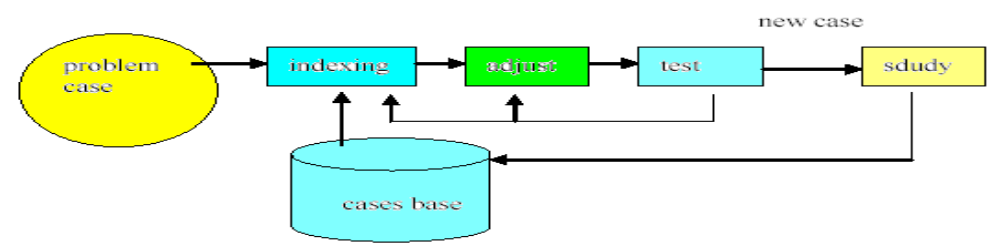

Figure-1: The principle figure of CBR system

The process of CBR includes five steps, and they are retrieval, reuse, amending, review and system updating. To develop CBR system, the five steps are the core work. Whereas, the most important thing is that there are sufficient cases in case base. So, how to retrieve the cases from the case base is the key issue for CBR system. If there is no effective method for case retrieval, CBR system will become failure.

When indexing the case base, how to decide the similarity between the cases is very important. So, CBR system always is called similarity searching system. There are three typical CBR searching strategies, and they are nearest adjacent indexing method, inductive indexing, and knowledge guide method. Nevertheless, these methods are only suitable for the cases with qualitative attributes; they aren't competent for the cases with quantitative attributes, especially for the cases with fuzzy quantitative attributes. In practical applications of CBR system, there are large numbers of cases with quantitative attributes and qualitative attributes.

\section{The Analytic Hierarchy Process}

AHP ( The Analytic Hierarchy Process ) was presented by American operational research expert T.L.Satty in 1977. This method is a robust, flexible multi-criteria decision analysis tool. The AHP methodology is a decision-support procedure for dealing with complex, unstructured, and multi-criteria decisions [30]. Three basic steps of this methodology are as follows:

- Describing a complex decision making problem as a hierarchy.

- Using pair-wise comparison techniques in estimating the relative weights of various elements on each level of the hierarchy.

- Integrating the weights to develop an overall evaluation of the decision alternatives.

The concept of the fuzzy set theory was first introduced by Zadeh. It has been used as a modeling tool for complex systems that are difficult to define precisely or with certainty, but can be operated and controlled by humans. There are many fuzzy AHP methods proposed by a number of researchers. The earliest research in the fuzzy AHP was appeared in Van Laarhoven and Pedrycz [32]. Chang [33] introduced a new approach to fuzzy AHP and proposes triangular fuzzy numbers for pair-wise comparison scale of fuzzy AHP in his model. The comparison formula of comparative importance of all criteria is shown as Table.2:

\begin{tabular}{|c|c|c|c|}
\hline Described by natural language & Value & Described by natural language & Value \\
\hline Important alike & 1 & More important & 7 \\
\hline Comparative important & 3 & Absolute important & 9 \\
\hline Very important & 5 & Middle value & $2,4,6,8$ \\
\hline
\end{tabular}

Table.2: The comparison formula of comparative importance of all criteria 


\section{Literature Review}

Various approaches had been proposed in the past to help address the issue of material selection. Ashby et al. [1] provided a comprehensive review of the strategies or methods for materials selection, from which three types of materials selection methodology had been identified such as (a) free searching based on quantitative analysis, (b) checklist/questionnaire based on expertise capture, and (c) inductive reasoning and analog procedure. For the free-searching method, there are already a number of well documented methods, the most famous being the graphical engineering selection method or the ranking method [2, 3]. Edwards [4] developed a checklist/questionnaire method to improve the likelihood of achieving an optimal design solution. Some knowledge based systems developed by researchers for materials selection include that of Sapuan [5], Amen and Vomacka [6], Zha [7] and Jalham [8]. However, these systems and methods are complex and knowledge intensive. Jee and Kang [9] proposed TOPSIS method for material selection.

Shanian and Savadogo $[10,11]$ presented material selection models using an MADM method known as ELECTRE. However, ELECTRE method uses the concept of outranking relationship and the procedure is rather lengthy. In another work, Shanian and Savadogo [12] proposed TOPSIS method for material selection of metallic bipolar plates for polymer electrolyte fuel cell. However, the TOPSIS method proposed by them does not take into account the qualitative nature of the material selection attributes.

Furthermore, the 'entropy' concept used by the authors for deciding the relative importance of attributes does not give scope to designer's preferences and it involves more computation. Rao [13] presented a material selection model using graph theory and matrix approach. However, the method does not have a provision for checking the consistency made in the judgments of relative importance of the attributes. Manshadi et al. [14] proposed a numerical method for materials selection combining non-linear normalization with a modified digital logic method. However, the method does not make a provision for considering the qualitative material selection attributes. Chan and Tong [15] proposed weighted average method using grey relational analysis to rank the materials with respect to certain quantitative attributes. Rao [16] proposed a compromise ranking method known as VIKOR and Chatterjee et al. [17] proposed VIKOR and ELECTRE methods for material selection.

Fayazbakhsh et al. [18] used Z-transformation in statistics for normalization of material properties for materials selection in mechanical design. Khabbaz et al. [19] proposed a fuzzy logic approach for material selection. However, the procedure needs many fuzzy IF-THEN rules and the quantitative values of the attributes are to be converted to fuzzy descriptions to it into the fuzzy rules.

Maniya and Bhatt [20] proposed preference selection index (PSI) method for material selection. The method uses only the objective weights of the attributes and does not take into consideration the decision maker's expertise and judgment. Furthermore, the method does not have enough mathematically validity and no separate steps were suggested for conversion of a qualitative attribute into a quantitative one. Jahan et al. [21] reviewed various material screening and choosing methods. In another work, Jahan et al. [22] proposed a linear assignment technique for material selection. However, the linear assignment technique may not be as precise as other COPRAS methods when the manufacturing system selection is based on quantitative and qualitative properties.

Keeping in view of the above research works on manufacturing selection, a novel decision making method is proposed in this paper for manufacturing selection for a given intelligent manufacturing system. The aim of the present paper is to propose a novel COPRAS method to deal with the manufacturing system selection problems considering both qualitative and quantitative attributes. A ranked value judgment on a fuzzy conversion scale for the qualitative attributes is introduced. The proposed method helps the decision maker to arrive at a decision based on either the objective weights of importance of the attributes or his/her subjective preferences or considering both the objective weights and the subjective preferences.

\section{Complex proportional assessment method (COPRAS)}

This preference ranking method of complex proportional assessment (COPRAS), mainly developed by Zavadskas et al. [22], assumes direct and proportional dependences of the significance and utility degree of the available alternatives under the presence of mutually conflicting criteria. It takes into account the performance of the alternatives with respect to different criteria and the corresponding criteria weights. This method selects the best decision considering both the ideal and the ideal-worst solutions.

The COPRAS method which is used here for evaluating and selecting the alternative materials for the given engineering problems uses a stepwise ranking and evaluating procedure of the alternatives in terms of their significance and utility degree. This method has already been successfully applied to solve various problems in the field of construction [22-26], property management, economics, etc. The procedural steps of COPRAS method are presented as below. 
- $\quad$ Step 1: Develop the initial decision matrix, $X$.

$$
X=\left[x_{i j}\right]_{m x n}=\left[\begin{array}{cccc}
x_{11} & x_{12} & \ldots & x_{1 n} \\
x_{21} & x_{22} & \ldots & x_{2 n} \\
\ldots & \ldots & \ldots & \ldots \\
x_{m 1} & x_{m 2} & \ldots & x_{m n}
\end{array}\right]
$$

Where $\mathrm{x}_{\mathrm{ij}}$ is the performance value of ith alternative on jth criterion, $\mathrm{m}$ is the number of alternatives compared and $\mathrm{n}$ is the number of criteria.

The decision table, given in Table 3, shows alternatives, Ai (for $\mathrm{i}=1,2, \ldots, n$ ), attributes, $B \mathrm{j}$ (for $\mathrm{j}=$ $1,2, \ldots, m$ ), weights of attributes, $w j$ (for $j=1,2, \ldots, m$ ) and the measures of performance of alternatives, xij (for $\mathrm{i}=1,2, \ldots, \mathrm{n} ; \mathrm{j}=1,2, \ldots, \mathrm{m}$ ). Given the decision table information and a decision making method, the task of the decision maker is to find the best alternative and/or to rank the entire set of alternatives.

\begin{tabular}{cllllll}
\hline Alternatives & \multicolumn{6}{l}{ Attributes } \\
\cline { 2 - 7 } & $B_{1}$ & $B_{2}$ & $B_{3}$ & - & - & $B_{m}$ \\
& $\left(w_{1}\right)$ & $\left(w_{2}\right)$ & $\left(w_{3}\right)$ & $(-)$ & $(-)$ & $\left(w_{m}\right)$ \\
\hline$A_{1}$ & $x_{11}$ & $x_{12}$ & $x_{13}$ & - & - & $x_{1 m}$ \\
$A_{2}$ & $x_{21}$ & $x_{22}$ & $x_{23}$ & - & - & $x_{2 m}$ \\
$A_{3}$ & $x_{31}$ & $x_{32}$ & $x_{33}$ & - & - & $x_{3 m}$ \\
- & - & - & - & - & - & - \\
- & - & - & - & - & - & - \\
$A_{n}$ & $x_{n 1}$ & $x_{n 2}$ & $x_{23}$ & - & - & $x_{m m}$ \\
\hline
\end{tabular}

Table-3: Multi-attribute decision matrix table

Identify the selection attributes for the considered material selection problem and short-list the materials on the basis of the identified attributes satisfying the requirements. The attributes are of two types, beneficial (i.e. higher values are desired) and non-beneficial (i.e. lower values are desired). A quantitative or qualitative value or its range may be assigned to each identified attribute as a limiting value or threshold value for its acceptance for the considered problem. An alternative with each of its attribute, meeting the acceptance value, may be short-listed.

- Step 2: Normalize the decision matrix using the following equation. The purpose of normalization is to obtain dimensionless values of different criteria so that all of them can be compared.

$$
R=\left[r_{i j}\right]_{m x n}=\frac{x_{i j}}{\sum_{i=1}^{m} x_{i j}}
$$

- Step 3: Determine the weighted normalized decision matrix, D.

$$
D=\left[y_{i j}\right]_{m x n}=r_{i j} x w_{j} \quad(i=1,2, \ldots, m ; j=1,2, \ldots, n)
$$

Where $\mathrm{r}_{\mathrm{ij}}$ is the normalized performance value of ith alternative on $\mathrm{jth}$ criterion and $\mathrm{w}_{\mathrm{j}}$ is the weight of jth criterion. The sum of dimensionless weighted normalized values of each criterion is always equal to the weight for that criterion.

$$
\sum_{i=1}^{m} y_{i j}=w_{j}
$$

In other words, it can be said that the weight, $\mathrm{w}_{\mathrm{j}}$ of the investigated criterion is proportionally distributed among all the alternatives according to their weighted normalized value, $\mathrm{y}_{\mathrm{ij}}$. 
- Step 4: The sums of weighted normalized values are calculated for both the beneficial attributes and non-beneficial attributes. The lower is the value of a non-beneficial attribute, such as price, the better is the attainment of goal. On the other hand, the greater is the value of a beneficial attribute, such as quality, the better is the attainment of goal.

These sums are calculated using the following equations:

$$
\begin{gathered}
S_{+i}=\sum_{j=1}^{n} y_{+i j} \\
S_{-i}=\sum_{j=1}^{n} y_{-i j}
\end{gathered}
$$
respectively.

Where $\mathrm{y}_{+\mathrm{ij}}$ and $\mathrm{y}_{-} \mathrm{ij}$ are the weighted normalized values for the beneficial and non-beneficial attributes

The greater the value of $\mathrm{S}_{+\mathrm{i}}$, the better is the alternative, and the lower the value of $\mathrm{S}_{\mathrm{i}}$, the better is the alternative. The $S_{+\mathrm{i}}$ and $\mathrm{S}_{\mathrm{i}}$ values express the degree of goals attained by each alternative. In any case, the sums of 'pluses' $S_{+i}$ and 'minuses' $S_{-}$of the alternatives are always respectively equal to the sums of weights for the beneficial and non-beneficial attributes as expressed by the following equations:

$$
\begin{aligned}
& S_{+}=\sum_{i=1}^{m} S_{+i}=\sum_{i=1}^{m} \sum_{j=1}^{n} y_{+i j} \\
& S_{-}=\sum_{i=1}^{m} S_{-i}=\sum_{i=1}^{m} \sum_{j=1}^{n} y_{-i j}
\end{aligned}
$$

In this way, Equations (7) and (8) can be used to verify the calculations.

- Step 5: Determine the significances of the alternatives on the basis of defining the positive alternatives $S_{+\mathrm{i}}$ and negative alternatives $S_{-}$characteristics.

- Step 6: Determine the relative significances or priorities of the alternatives. The priorities of the candidate alternatives are calculated on the basis of Qi. The greater the value of Qi, the higher is the priority of the alternative. The relative significance value of an alternative shows the degree of satisfaction attained by that alternative. The alternative with the highest relative significance value $\left(Q_{\max }\right)$ is the best choice among the candidate alternatives.

Relative significance value (priority), Qi of ith alternative can be obtained as below:

$$
Q_{i}=S_{+i}+\frac{S_{-\min } \sum_{i=1}^{m} S_{-i}}{S_{-i} \sum_{i=1}^{m}\left(1 / S_{-i}\right)} \quad(i=1,2, \ldots, m)
$$

Where $S_{- \text {min }}$ is the minimum value of $S_{-} \mathrm{i}$.

- Step 7: Calculate the quantitative utility (Ui) for ith alternative. The degree of an alternative's utility is directly associated with its relative significance value (Qi). The degree of an alternative's utility, leading to a complete ranking of the candidate alternatives, is determined by comparing the priorities of all the alternatives with the most efficient one and can be denoted as below:

$$
U_{i}=\left[\frac{Q_{i}}{Q_{\max }}\right] \times 100 \%
$$


Where $\mathrm{Q}_{\max }$ is the maximum relative significance value. With the increase or decrease in the value of the relative significance for an alternative, it is observed that its degree of utility also increases or decreases [22].

These utility values of the candidate alternatives range from $0 \%$ to $100 \%$. Thus, this approach allows for evaluating the direct and proportional dependence of significance and utility degree of the considered alternatives in a decision-making problem involving multiple criteria, their weights and performance values of the alternatives with respect to all the criteria.

It may be added here that Equation (1) can deal with quantitative attributes. However, there exists some difficulty in the case of qualitative attributes (i.e. quantitative value is not available). A ranked value judgment on a fuzzy conversion scale is proposed in this paper by using fuzzy set theory. This approach is based on the work of Chen and Hwang [23]. The presented numerical approximation system systematically converts linguistic terms to their corresponding fuzzy numbers. An 11-point scale is proposed in this paper for better understanding and representation of the qualitative attribute. Table 4 is suggested which represents the selection attribute on a qualitative scale using fuzzy logic, corresponding to the fuzzy conversion scale shown in Fig. and helps the users in assigning the values. Once a qualitative attribute is represented on a scale then the alternatives can be compared with each other on this attribute in the same manner as that for quantitative attributes. One may refer to Rao and Parnichkun [24] for more details about how this scale is prepared.

\begin{tabular}{lll} 
Values of selection attribute. & \\
\hline $\begin{array}{l}\text { Qualitative measures of selection } \\
\text { attribute }\end{array}$ & $\begin{array}{l}\text { Fuzzy } \\
\text { number }\end{array}$ & $\begin{array}{l}\text { Assigned crisp } \\
\text { score }\end{array}$ \\
\hline Exceptionally low & $\mathrm{M}_{1}$ & 0.0455 \\
Extremely low & $\mathrm{M}_{2}$ & 0.1364 \\
Very low & $\mathrm{M}_{3}$ & 0.2273 \\
Low & $\mathrm{M}_{4}$ & 0.3182 \\
Below average & $\mathrm{M}_{5}$ & 0.4091 \\
Average & $\mathrm{M}_{6}$ & 0.5000 \\
Above average & $\mathrm{M}_{7}$ & 0.5909 \\
High & $\mathrm{M}_{8}$ & 0.6818 \\
Very high & $\mathrm{M}_{9}$ & 0.7727 \\
Extremely high & $\mathrm{M}_{10}$ & 0.8636 \\
Exceptionally high & $\mathrm{M}_{11}$ & 0.9545 \\
\hline
\end{tabular}

Table-4: values of the selection attribute

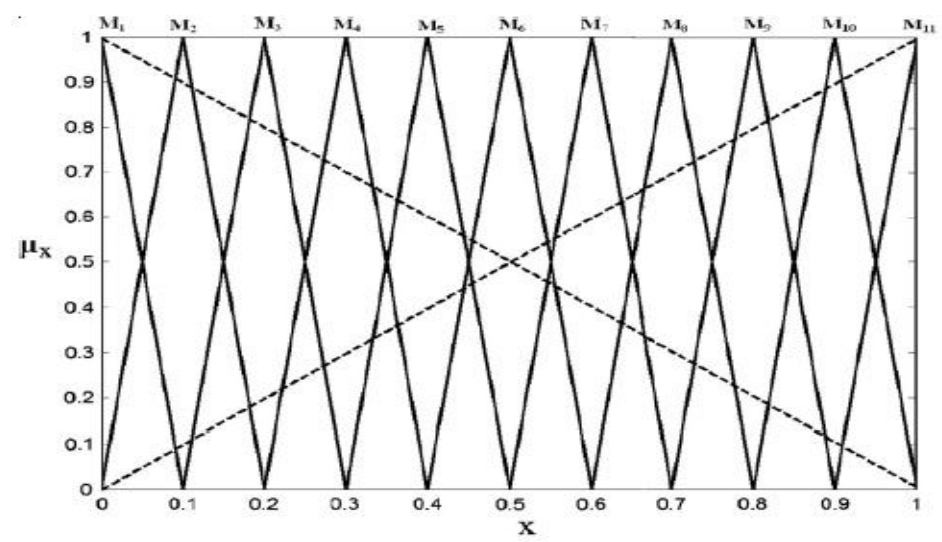

Figre-2: Linguistic terms to fuzzy numbers conversion (11-point scale).

\section{Case study: Selection of best manufacturing system}

Prepare the decision matrix for evaluating the weight factor by applying the AHP method. Selection the criteria and alternatives of intelligent manufacturing system with respect to benefit and cost (non-benefit) criteria.

Basically, we consider the three types of intelligent manufacturing system i.e. known as alternatives. The different criteria are to be considered as quality, cost, lead time, service level, product variety and robustness. Finally, each and every product should be minimum cost and minimum lead time with the best quality, product variety, very good service level and maximum robustness. The different alternatives are lean manufacturing system $\left(\mathrm{A}_{1}\right)$, agile manufacturing system $\left(\mathrm{A}_{2}\right)$ and le-agile manufacturing system $\left(\mathrm{A}_{3}\right)$. 
Table-4: criteria's of the intelligent manufacturing system

\begin{tabular}{|c|c|c|c|}
\hline Criteria & Criterion & Benefit criteria & Non-benefit criteria \\
\hline $\mathrm{C}_{1}$ & Quality & $\bullet(+)$ & - \\
\hline $\mathrm{C}_{2}$ & Cost & - & $\bullet$ \\
\hline $\mathrm{C}_{3}$ & Lead time & & $(-)$ \\
\hline $\mathrm{C}_{4}$ & Service level & $\bullet \quad(+)$ & - \\
\hline $\mathrm{C}_{5}$ & Product variety & $\bullet \quad(+)$ & - \\
\hline $\mathrm{C}_{6}$ & Robustness & $\bullet \quad(+)$ & - \\
\hline
\end{tabular}
his scale.

Now, we are generating the primary decision matrix from the AHP method introduced by T.L.Satty and

Table-5: AHP matrix from the Satty scale

\begin{tabular}{|c|c|c|c|c|c|c|}
\hline & $(+) \mathbf{C}_{\mathbf{1}}$ & $(-) \mathbf{C}_{\mathbf{2}}$ & $\mathbf{( - ) \mathbf { C } _ { 3 }}$ & $\mathbf{( + ) \mathbf { C } _ { \mathbf { 4 } }}$ & $\mathbf{( + ) \mathbf { C } _ { \mathbf { 5 } }}$ & $\mathbf{( + )}_{\mathbf{6}}$ \\
\hline $\mathbf{C}_{\mathbf{1}}$ & 1 & 9 & 5 & 3 & 5 & 7 \\
\hline $\mathbf{C}_{\mathbf{2}}$ & $1 / 9$ & 1 & 2 & 3 & 4 & 3 \\
\hline $\mathbf{C}_{\mathbf{3}}$ & $1 / 5$ & $1 / 2$ & 1 & 2 & 3 & 2 \\
\hline $\mathbf{C}_{\mathbf{4}}$ & $1 / 3$ & $1 / 5$ & $1 / 3$ & 1 & $1 / 5$ & $1 / 7$ \\
\hline $\mathbf{C}_{\mathbf{5}}$ & $1 / 5$ & $1 / 3$ & $1 / 2$ & 5 & 1 & $1 / 3$ \\
\hline $\mathbf{C}_{\mathbf{6}}$ & $1 / 7$ & $1 / 2$ & $1 / 2$ & $1 / 3$ & 5 & 1 \\
\hline
\end{tabular}

The weight factors we are getting from the above matrix;-

$\left[\mathrm{C}_{1}\right]^{\mathrm{W}}=0.5072,\left[\mathrm{C}_{2}\right]^{\mathrm{W}}=0.1751,\left[\mathrm{C}_{3}\right]^{\mathrm{W}}=0.1276,\left[\mathrm{C}_{4}\right]^{\mathrm{W}}=0.0363, \quad\left[\mathrm{C}_{5}\right]^{\mathrm{W}}=0.0765, \quad\left[\mathrm{C}_{6}\right]^{\mathrm{W}}=0.0773$ Main decision matrix of the intelligent manufacturing system given in below:-

Table-6: Relation in between alternatives-criteria's from fuzzy scale

\begin{tabular}{|c|c|c|c|c|c|c|}
\hline & $(+) \mathbf{C}_{\mathbf{1}}$ & $(-) \mathbf{C}_{\mathbf{2}}$ & $(-) \mathbf{C}_{\mathbf{3}}$ & $\left(\mathbf{+} \mathbf{C}_{\mathbf{4}}\right.$ & $\left(\mathbf{+} \mathbf{C}_{\mathbf{5}}\right.$ & $\mathbf{( + )}_{\mathbf{6}}$ \\
\hline $\mathbf{A}_{\mathbf{1}}$ & Good & Very good & Good & Good & Poor & Poor \\
\hline $\mathbf{A}_{\mathbf{2}}$ & Good & Good & Good & Very good & Very good & Very good \\
\hline $\mathbf{A}_{\mathbf{3}}$ & Good & Very good & Good & very good & Good & Good \\
\hline
\end{tabular}

Now, we are generating the actual decision matrix using the values of fuzzy numbers:-

Table-7: Fuzzy values of the decision matrix of IMS

\begin{tabular}{|l|l|l|l|l|l|l|}
\hline & $(\mathbf{+}) \mathbf{C}_{\mathbf{1}}$ & $\mathbf{( - ) \mathbf { C } _ { 2 }}$ & $\mathbf{( - ) \mathbf { C } _ { 3 }}$ & $\mathbf{( + ) \mathbf { C } _ { 4 }}$ & $\mathbf{( + ) \mathbf { C } _ { \mathbf { 5 } }}$ & $\mathbf{( + )}_{\mathbf{6}}$ \\
\hline $\mathbf{A}_{\mathbf{1}}$ & 0.6818 & 0.7727 & 0.6818 & 0.6818 & 0.3182 & 0.3818 \\
\hline
\end{tabular}


An Exploratory Analysis of Intelligent Manufacturing System (Ims) Under Fuzzy Utopian

\begin{tabular}{|l|l|l|l|l|l|l|}
\hline $\mathbf{A}_{\mathbf{2}}$ & 0.6818 & 0.6818 & 0.6818 & 0.7727 & 0.7727 & 0.7727 \\
\hline $\mathbf{A}_{\mathbf{3}}$ & 0.6818 & 0.7727 & 0.6818 & 0.7727 & 0.6818 & 0.6818 \\
\hline $\mathbf{S u m}$ & 2.0454 & 2.2272 & 2.0454 & 2.2272 & 1.7727 & 1.7727 \\
\hline
\end{tabular}

The normalized decision matrix generating from the actual decision matrix from the equation-[2]

Table-8: Normalized decision matrix of IMS

\begin{tabular}{|c|c|c|c|c|c|c|}
\hline & $(\mathbf{+}) \mathbf{C}_{\mathbf{1}}$ & $\mathbf{( - ) \mathbf { C } _ { \mathbf { 2 } }}$ & $\mathbf{( - ) \mathbf { C } _ { \mathbf { 3 } }}$ & $\mathbf{( + )} \mathbf{C}_{\mathbf{4}}$ & $\mathbf{( + )} \mathbf{C}_{\mathbf{5}}$ & $\mathbf{( + ) \mathbf { C } _ { \mathbf { 6 } }}$ \\
\hline $\mathbf{A}_{\mathbf{1}}$ & 0.3333 & 0.3469 & 0.3333 & 0.3061 & 0.1795 & 0.1795 \\
\hline $\mathbf{A}_{\mathbf{2}}$ & 0.3334 & 0.3061 & 0.3334 & 0.3469 & 0.4359 & 0.4359 \\
\hline $\mathbf{A}_{\mathbf{3}}$ & 0.3333 & 0.3469 & 0.3333 & 0.3469 & 0.3846 & 0.3846 \\
\hline
\end{tabular}

Now, we formulated the weighted normalized decision matrix from the normalized decision matrix from the equation-[3] and equation-[4].

Table-9: Weighed Normalized decision matrix

\begin{tabular}{|c|l|l|l|l|l|l|}
\hline & $(+) \mathbf{C}_{\mathbf{1}}$ & $\mathbf{( - ) \mathbf { C } _ { 2 }}$ & $\mathbf{( - ) \mathbf { C } _ { \mathbf { 3 } }}$ & $\mathbf{( + ) \mathbf { C } _ { \mathbf { 4 } }}$ & $\mathbf{( + ) \mathbf { C } _ { \mathbf { 5 } }}$ & $\mathbf{( + ) \mathbf { C } _ { \mathbf { 6 } }}$ \\
\hline Weight factor & $\mathbf{0 . 5 0 7 2}$ & $\mathbf{0 . 1 7 5 1}$ & $\mathbf{0 . 1 2 7 6}$ & $\mathbf{0 . 0 3 6 3}$ & $\mathbf{0 . 0 7 6 5}$ & $\mathbf{0 . 0 7 7 3}$ \\
\hline $\mathbf{A}_{\mathbf{1}}$ & 0.1690 & 0.0607 & 0.0425 & 0.0111 & 0.0137 & 0.0139 \\
\hline $\mathbf{A}_{\mathbf{2}}$ & 0.1691 & 0.0536 & 0.0426 & 0.0126 & 0.0333 & 0.0337 \\
\hline $\mathbf{A}_{3}$ & 0.1690 & 0.0607 & 0.0425 & 0.0140 & 0.0294 & 0.0297 \\
\hline
\end{tabular}

Benefit and non-benefit or cost attributes value getting from the equations of [5, 6, 7 and 8].

Table-10: Benefit and Non-benefit attributes value

\begin{tabular}{|c|c|c|c|c|}
\hline & $\mathbf{S i}^{+}$ & Value & $\mathbf{S i}^{-}$ & Value \\
\hline $\mathbf{A}_{\mathbf{1}}$ & $\mathrm{S}_{1}{ }^{+}$ & 0.2077 & $\mathrm{~S}_{1}{ }^{-}$ & 0.1032 \\
\hline $\mathbf{A}_{\mathbf{2}}$ & $\mathrm{S}_{2}{ }^{+}$ & 0.2487 & $\mathrm{~S}_{2}{ }^{-}$ & 0.0962 \\
\hline $\mathbf{A}_{3}$ & $\mathrm{~S}_{3}{ }^{+}$ & 0.2421 & $\mathrm{~S}_{3}{ }^{-}$ & 0.1032 \\
\hline
\end{tabular}

Relative and maximum relative significance values generating from the equation of [9 and10].

Table-11: Relative and maximum relative significance value with the rank of alternatives

\begin{tabular}{|c|c|c|c|}
\hline & $\mathbf{Q}_{\mathbf{i}}$ & $\mathbf{P}_{\mathbf{i}}(\mathbf{\%})$ & Rank \\
\hline $\mathbf{A}_{\mathbf{1}}$ & 0.3065 & 86.41 & $\mathbf{3}$ \\
\hline $\mathbf{A}_{\mathbf{2}}$ & 0.3547 & 100 & $\mathbf{1}$ \\
\hline $\mathbf{A}_{3}$ & 0.3409 & 96.11 & $\mathbf{2}$ \\
\hline
\end{tabular}




\section{Discussion}

"Agility" is needed in less predictable environments where demand is volatile and the requirement for variety is high (Lee, 2002). "Lean" works best in high volume, low variety and predictable environments. Leagility is the combination of the lean and agile paradigm within a CBR -MCDM strategy by positioning the decoupling point so as to best suit the need for responding to a volatile demand downstream yet providing level scheduling upstream from the de-coupling point (Naylor et al., 1999; Bruce et al., 2004).

The MADM, MOORA, SAW, COPRAS, EVAMIX, TOPSIS and VIKOR methods are mathematically simple to moderately complex to understand, and take almost the same calculation/computation time. But in case of AHP method, as the decision maker has to pair-wise compare all the considered manufacturing system alternatives with respect to different criteria, for each such pair-wise comparison matrix, the decision maker has also to check the consistency of that matrix. In AHP, if a pair-wise comparison matrix is found to be inconsistent (consistency ratio >0.10). From the mathematical point of view, AHP is a complex and lengthy process.

The basic algorithm of EVAMIX combines the characteristics of cardinal and ordinal data, designed to combine the output in a single appraisal score which gives it much greater flexibility than any other MCDM method [28] and also allows the decision maker to use all the data available in its original form. Whereas, COPRAS method enables the decision maker to obtain a reduced criterion while determining the overall efficiency of the considered alternatives.

This generalized criterion is directly proportional to the relative effect of the values and weights of the considered criteria [23]. The COPRAS, TOPSIS and VIKOR methods are more efficient in dealing with the tangible attributes but they cannot deal very well if the criteria values are expressed qualitatively. Whereas, AHP can also deal with tangible as well as non-tangible attributes, especially where the subjective judgments of different individuals constitute an important part of the decision-making process. But in some cases, unmanageable number of pair-wise comparisons of attributes and alternatives with respect to each of the attributes may result. As the number of alternatives increases, the amount of calculations rises quite rapidly and computational procedures become quite elaborate.

Table 12 compares the performance of COPRAS, EVAMIX, TOPSIS, VIKOR and AHP, MOORA, SAW, ELECTRE methods with respect to calculation/computation time, simplicity, transparency, possibility of graphical interpretation and type of the information [35].

\begin{tabular}{|c|c|c|c|c|}
\hline MCDM methods & Calculation time & Simplicity & Transparency & flexibility \\
\hline COPRAS & Less & Simple & Very good & Very high \\
\hline EVAMIX & Moderate & Moderately & Critical & Low \\
\hline ELECTRE & Moderate & Moderately & Critical & Low \\
\hline TOPSIS \& AHP & High & Moderately & Good & High \\
\hline VIKOR & Less & Simple & Very good & Moderate \\
\hline MADM & Moderate & Moderately & Critical & High \\
\hline MOORA & Less & Simple & Good & High \\
\hline SAW & Less & Simple & Good & High \\
\hline
\end{tabular}

Transparency is one of the important factors that need to be addressed for selecting a particular MCDM method for a specific problem. Different decision-making methods have different levels of transparency. It is always recommended and desirable not to use a highly complex MCDM method with lack of transparency (as in case of AHP) as it makes very difficult for the decision maker to identify any mistake made during the calculation process which may often lead to a very high degree of risk involvement by misleading the entire selection process.

A final decision can be taken keeping in view of the practical considerations. All possible constraints likely to be experienced by the user have to be considered. These include constraints such as manufacturing lead-time constraints, manufacturing process constraints, economic constraints, management constraints, social constraints, and political constraints. If the first choice manufacturing system as decided by the results of those COPRAS methods that have a very significant positive Spearman's rank correlation coefficient can not be 
considered due to certain constraints, then the user may opt for the second choice manufacturing system. If the second choice manufacturing system also can not be considered due to certain constraints, then the user may opt for the third choice manufacturing system.

\section{Conclusions}

Leanness in a CBR-MCDM maximizes profits through cost reduction while agility maximizes profit through providing exactly what the customer requires. The le-agile manufacturing system enables the upstream part of the chain to be cost-effective and the downstream part to achieve high service levels in a volatile marketplace.

The decision maker can easily apply COPRAS method to evaluate the alternatives and select the most suitable manufacturing system, while being completely unaware of the physical meaning of the decision-making process. Moreover, this method allows for the formulation of a reduced performance criterion which is directly proportional to the relative effect of the compared criteria values. On the other hand, the main advantage of COPRAS method is that unlike the other MCDM methods, it employs separate mathematical models to benefit the non-benefit and very good graphical qualitative criteria of the decision matrix. Due to this added advantage, in COPRAS method, the chance of loosing information is very small. The COPRAS method, which is quite flexible and easy to comprehend, also segregates the subjective part of the evaluation process into criteria weights including decision using a combined multiple attribute decision-making method.

It integrates various criteria, enablers and alternatives in decision model. The approach also captures their relationships and interdependencies across and along the hierarchies. It is effective as both quantitative and qualitative characteristics can be considered simultaneously without sacrificing their relationships

Finally, CPRAS is a very mature and stable method. Moreover; CBR is a scientific decision method. According to the instance presented above, the case indexing model for CBR-IMS system based on COPRAS-AHP is an effective and feasible method. Of course, CPORAS is improved after the research of experts and scholars. For example, the fuzzy AHP-COPRAS are a more scientific method. In our subsequent work, we are adopting fuzzy AHP in CBR-IMS system.

\section{ACKNOWLEDGMENT}

The authors wish to thank Jadavpur University, Kolkata, India and Indian Institute of Management (IIMC), Kolkata, India for their valuable literature supports in making this research successfully.

\section{REFERENCES}

[1] R. Booth, Agile manufacturing, Engineering Management Journal 6 (2) (1996) 105$\} 112$

[2] C. Ward, What is Agility, Industrial Engineering, November (1994) 14\}16

[3] J. Stevens, Integrating the supply chain, International Journal of Physical Distribution and Materials Management 19 (8) (1989) 3 \}8.

[4] M.M. Naim, The book that changed the world. Manufacturing Engineer, February (1997) 13$\} 16$.

[5] S. Hoekstra, J. Romme, Integral Logistics Structures: Developing Customer Oriented Goods Flow, McGraw-Hill, London, 1992.

[6] T. Hill, Manufacturing Strategy, 2nd Ed., MacMillan, London, 1993.

[7] P.T. Kidd, Agile Manufacturing: A Strategy for the $21^{\text {st }}$ Century. IEE Agile Manufacturing Colloquium 1995, pp. 1/1 \}1/6.

[8] J.P. Womack, D.T. Jones, D. Roos, the Machine That Changed the World, Rawson Associates, New York, 1990.

[9] G. Stalk Jr, T.M. Hout, Competing Against Time: How Time-Based Competition Is Reshaping Global Markets, The Free Press, New York, 1990.

[10] G.N. Evans, M.M. Naim, D.R. Towill, Process costing\} the route to construction re-engineering. Mouchel centenary conference, in: M.B. Leeming, B.H.V. Topping (Eds.), Innovation in Civil and Construction Engineering, Civil-Comp Press, Edinburgh, 1997, pp. $153\} 162$.

[11] R.H. Hayes, G.P. Pisano, Beyond world class: The new manufacturing Strategy. Harvard Business Review, January\} February (1994) 77\} 86.

[12] H.J. GruK nwald, L. Fortuin, Many steps towards zero inventory, European Journal of Operational Research 59 (1992) 359$\} 369$.

[13] J.P. Womack, D.T. Jones, Lean Thinking: Banish Waste and Create Wealth in Your Corporation, Simon \& Schuster, New York, 1996.

[14] S.L. Goldman, R.N. Nagel, K. Preiss, Agile Competitors and Virtual Organisations: Strategies for Enriching, Van Nostrand Reinhold, UK, 1994.

[15] A. Harrison, The impact of schedule stability on supplier responsiveness: A comparative study. Second International Symposium on Logistics, 11\}12 July 1995, Nottingham, UK, pp. 217\}224.

[16] Anon. The Jumbo Stumbles. The Economist, $11^{\text {th }}$ October, 1997, p. 116.

[17] A. Harrison, 1997. Investigating the sources and causes of schedule instability, Third International Symposium on Logistics, 9$\} 11$ July 1997, Padua, Italy, pp. 155\}164.

[18] J.M. Lehtonen, J. HolmstroK m, J. Slotte, Balancing product range and capacity within the customer acceptable delivery time in implosive industries, 9th International Working Seminar on Production Economics, vol. 3, 1996, pp. 333$\} 346$.

[19] M.L. Fisher, J.H. Hammond, W.R. Obermeyer, A. Raman, Making supply meet demand in an uncertain world, Harvard Business Review, May\}June (1994) 83$\} 93$.

[20] Chan JWK, Tong TKL. Multi-criteria material selections and end-of-life product strategy: grey relational analysis approach. Mater Des 2007; 28:1539-46.

[21] Rao RV. A decision making methodology for material selection using an improved compromise ranking method. Mater Des 2008; 29:1949-54.

[22] Zavadskas EK, Kaklauskas A, Turskis Z, Tamošaitien J. Selection of the effective dwelling house walls by applying attributes values determined at intervals. J Civil Eng Manage 2008; 14:85-93. 
[23] Kaklauskas A, Zavadskas EK, Trinkunas V. A multiple criteria decision support on-line system for construction. Eng Appl Artif Intell 2007; 20:163-75.

[24] Zavadskas EK, Turskis Z, Tamošaitieney J, Marina V. Multi-criteria selection of project managers by applying grey criteria. Technol Economic Develop Economy, Baltic J Sustain 2008; 14:462-77.

[25] Kaklauskas A, Zavadskas EK, Raslanas S, Ginevicius R, Komka A, Malinauskas P. Selection of low-e windows in retro.t of public buildings by applying multiple criteria method COPRAS: a Lithuanian case. Energy Build 2006; 38:454-62.

[26] Zavadskas EK, Kaklauskas A, Peldschus F, Turskis Z. Multi-attribute assessment of road design solutions by using the COPRAS method. Baltic J Road Bridge Eng 2008; 2:195-203.

[27] Martel JM, Matarazzo B. Other outranking approaches. In: Figueira J, Salvatore G, Ehrgott M, editors. Multiple criteria decision analysis: state of the art surveys. Springer: New York; 2005. p. 197-262.

[28] Hajkowicz S, Higgins A. A comparison of multiple criteria analysis techniques for water resource management. Euro J Oper Res 2008; 184:255-65.

[29] Chung E-S, Lee KS. Identification of spatial ranking of hydrological vulnerability using multi-criteria decision making techniques: case study of Korea. Water Res Manage doi: 10.1007/s11269-008-9387-9.

[30] Ustinovichius L, Zavadskas EK, Podvezko V. Application of a quantitative multiple criteria decision making (MCDM-1) approach to the analysis of investments in construction. Control Cybern 2007; 36:251-68.

[31] Jeffreys I. The use of compensatory and non-compensatory multi-criteria analysis for small-scale forestry. Small-scale Forest Ecol Manage Policy 2004; 3:99-117.

[32] Macharis C, Springael J, Brucker KD, Verbeke A. PROMETHEE and AHP: the design of operational synergies in multi-criteria analysis: strengthening PROMETHEE with ideas of AHP. Euro J Oper Res 2004; 153:307-17.

[33] Triantaphyllou E. Multi-criteria decision making methods: a comparative study. Dordrecht: Kluwer Academic Publishers; 2000.

[34] Pérez J, Jimeno JL, Mokotoff E. Another potential shortcoming of AHP. TOP: Off J Spanish Soc Stat Oper Res 2006; 14:99-111.

[35] Ginevic;ius R, Podvezko V. Multi-criteria graphical-analytical evaluation of the financial state of construction enterprises. Baltic J Sustain 2008; 14:452-61.

[36] Edwards W, Newman JR. Multiattribute evaluation. In: Arkes HR, Hammond KR, editors. Judgment and decision making: an interdisciplinary reader. Cambridge: Cambridge University Press; 1986.

[37] Farag M. Quantitative methods of materials selection. In: Kutz M, editor. Handbook of materials selection; 2002.

[38] Triantaphyllou E. Multi-criteria decision making methods: a comparative study. London: Springer-Verlag; 2000.

[39] Rao RV. Decision making in the manufacturing environment using graph theory and fuzzy multiple attribute decision making methods. London: Springer-Verlag; 2007.

[40] Torrez JB. Light-weight materials selection for high-speed naval craft. PhD thesis, Massachusetts Institute of Technology; 2007.

[41] Ashby MF, Brechet YJM, Cebon D, Salvo L. Selection strategies for materials and processes. Mater Des 2004; 25:51-67.

[42] Ashby MF. Materials selection in mechanical design. New York: Pergamon Press; 1995.

[43] Ashby MF, Johnson K. Materials and design: the art and science of materials selection in product design. Oxford: Butterworth Heinemann; 2002.

[44] Edwards KL. Selecting materials for optimum use in engineering components. Mater Des 2005; 26:469-73.

[45] Sapuan SM. A knowledge-based system for materials selection in mechanical engineering design. Mater Des 2001; 22:687-95.

[46] Amen R, Vomacka P. Case-based reasoning as a tool for materials selection. Mater Des 2001; 22:353-8.

[47] Zha XF. A web-based advisory system for process and material selection in concurrent product design for a manufacturing environment. Int J Adv Manufacturing Technology 2005; 25(3-4):233-43.

[48] Jalham IS. Decision-making integrated information technology (IIT) approach for material selection. Int J Comput Appl in Technol 2006; 25:65-71.

[49] Jee DH, Kang KJ. A method for optimal material selection aided with decision making theory. Mater Des 2000; 21(3):199-206.

[50] Shanian A, Savadogo O. A material selection model based on the concept of multiple factor decision making. Mater Des 2006; 27:329-37.

[51] Shanian A, Savadogo O. A non-compensatory compromised solution for material selection of bipolar plates for polymer electrolyte membrane fuel cell (PEMFC) using ELECTRE IV. Electro-chim Acta 2006; 51:5307-15.

[52] Shanian A, Savadogo O. TOPSIS multiple-criteria decision support analysis for material selection of metallic bipolar plates for polymer electrolyte fuel cell. J Power Sour 2006; 159:1095-104.

[53] Rao RV. A material selection model using graph theory and matrix approach. Mater Sci Eng A 2006; 431:248-55.

[54] Manshadi BD, Mahmudi H, Abedian A, Mahmudi R. A novel method for materials selection in mechanical design: combination of non-linear normalization and a modified digital logic method. Mater Des 2007; 28:8-15.

[55] Chan JWK, Tong TKL. Multi-criteria material selections and end-of-life product strategy: a grey relational approach. Mater Des 2007; 28:1539-46.

[56] Rao RV. A decision making methodology for material selection using an improved compromise ranking method. Mater Des 2008; 29:1949-54.

[57] Chatterjee P, Athawale VM, Chakraborty S. Selection of materials using compromise ranking and outranking methods. Mater Des 2009; 30:4043-53.

[58] Fayazbakhsh K, Abedian A, Manshadi BD, Khabbaz RS. Introducing a novel method for materials selection in mechanical design using Z-transformation in statistics for normalization of material properties. Mater Des 2009; 30: 4396-404.

[59] Saaty TL. Fundamentals of decision making and priority theory with AHP. Pittsburg: RWS Publications; 2000. 